RESEARCH PAPER

\title{
Smoking, standard of living, and poverty in China
}

\author{
T-w Hu, Z Mao, Y Liu, J de Beyer, M Ong
}

Tobacco Control 2005;14:247-250. doi: 10.1136/tc.2004.010777

See end of article for authors' affiliations

....................

Correspondence to:

Professor Teh-wei Hu, PhD,

School of Public Health,

University of California,

Berkeley, Room 412

Warren Hall, Berkeley, CA

94720, USA; thu@

berkeley.edu

Received 3 December 2004

Accepted 18 May 2005

\begin{abstract}
Objectives: To analyse differences in smoking behaviour and smoking expenditures among low and high income households in China and the impact of smoking on standard of living of low income households in China.

Methods: About 3400 urban and rural households from 36 townships/districts in southwest China were interviewed in 2002. Cross tabulations and regression analysis were used to examine the differences in major household expenditures, including food, housing, clothing, and education between households with smokers and without smokers.

Results: Lower income households with smokers paid less per pack and smoked fewer cigarettes than higher income households with smokers. Poor urban households spent an average of $6.6 \%$ of their total expenditures on cigarettes; poor rural households spent $11.3 \%$ of their total expenditures on cigarettes.

Conclusion: Reducing cigarette expenditures could release household resources to spend on food, housing, and other goods that improve living standards.
\end{abstract}

S moking increases the risk of incurring cancers, cardiovascular disease, and other smoking related illnesses that result in higher medical expenditures, lower productivity, and premature death. Many international studies have addressed this long term negative impact of smoking on health and personal welfare. ${ }^{1-4}$ Smoking also has a short term immediate negative impact on household living standards, by diverting scarce household resources from essential expenditures. Cigarette expenditures can reduce the nutritional status of low income households by displacing expenditures on food. ${ }^{56}$ A study conducted in the Minhang district near Shanghai (1995) reported that smokers in 2716 households spent $17 \%$ of their household income on cigarettes. $^{7}$

China is the largest cigarette consuming country in the world, with more than 320 million smokers. ${ }^{89}$ In spite of recent rapid economic growth, China is still considered a low income country. Therefore, it is important to understand the relationships between smoking status, household standard of living, and poverty in China.

Low income and high income households differ in terms of the amount of tobacco consumed, types of cigarettes smoked (high price $v$ low price, foreign $v$ domestic brands), and cigarette expenditures. It has been asserted that, especially in developing countries, smoking takes up a large portion of the household budget of low income households, thus depriving them of money for essential expenditures. ${ }^{569}$ A concern is that an increase in the tobacco tax will increase the financial burden on low income smoking households. However, low income household smokers are likely to be more price sensitive; thus, they will quit or reduce their cigarette consumption by more than higher income households, so the increased burden of the tax will fall more heavily on high income households. ${ }^{10}$ This paper addresses the following two questions:

- What are the differences in smoking behaviour and smoking expenditures between low and high income households in China?

- What is the impact of smoking on the standard of living of low income households in China?

This information will allow policymakers and the general public to understand better the trade-off between smoking and living standards in China. It also will allow them to estimate whether and, if so, to what extent additional tobacco taxes will raise the financial burden of low income households.

\section{DATA SOURCES AND SAMPLE DESCRIPTIONS}

Data were collected in Sichuan Province, Guizhou Province, and the municipality of Chungqing, all in western China. The research team identified a total of 36 townships/districts and 108 villages/communities in the three sampling sites and contacted the randomly selected households with assistance from local administrative officials. Data were obtained through personal interviews with the heads of the households. The total study sample was 3404 households. Respondents were paid 5 Yuan per interview; the nonresponse rate was less than $1 \%$. The heads of the households were given a monthly diary for recording their household consumption and expenditures.

Table 1 presents a sociodemographic and economic description of the study sample. A large majority of the heads of households were male, particularly in the rural households. A large majority of urban households had three members, while four to five was typical for rural households. One limitation of these data is that they do not include age information for each individual household member; only the age of the head of the household was reported. A large majority of the heads of households was between the ages of 30-50 years. As expected, the heads of urban households had much higher education than the heads of rural households. Among urban households, $44 \%$ had members who smoke, while $79.7 \%$ of rural households had members who smoke. No information was collected about the number of smokers in each household. These data limitations mean that individuals could not be used as a unit of analysis. This paper focuses on household cigarette consumption and overall household expenditures.

The mean monthly household income was 2254 Yuan (or US\$274) for urban households and 872 Yuan (US\$106) for rural households. Since this paper pays special attention to the impact of smoking on expenditures among poor households, three income groups are specified. The Chinese government has defined separate income poverty criteria for urban and rural populations based on the income levels 
Table 1 Sociodemographic and economic characteristics of study-household sample

\begin{tabular}{|c|c|c|}
\hline & $\begin{array}{l}\text { Urban } \\
(n=2575)\end{array}$ & $\begin{array}{l}\text { Rural } \\
(n=829)\end{array}$ \\
\hline \multicolumn{3}{|l|}{ Head of household (\%) } \\
\hline Male & 62.0 & 91.0 \\
\hline Female & 38.0 & 9.0 \\
\hline \multicolumn{3}{|l|}{ Age of head of household (\%) } \\
\hline$\leqslant 30$ years & 34.3 & 26.9 \\
\hline $30-50$ years & 54.9 & 58.4 \\
\hline $50+$ years & 8.8 & 14.7 \\
\hline \multicolumn{3}{|l|}{ Size of household (\%) } \\
\hline$\leqslant 2$ & 14.0 & 4.9 \\
\hline 3 & 59.0 & 15.1 \\
\hline $4-5$ & 24.2 & 63.7 \\
\hline $6+$ & 2.8 & 16.3 \\
\hline \multicolumn{3}{|l|}{ Education (\%) } \\
\hline Illiterate & 0.7 & 12.4 \\
\hline Primary & 4.7 & 52.3 \\
\hline Junior high & 21.4 & 30.1 \\
\hline High school/vocational & 34.4 & 4.6 \\
\hline College + & 39.2 & 0.6 \\
\hline Smoking status (\%) & 44.0 & 79.7 \\
\hline Family monthly income (Yuan)* & 2254 & 872 \\
\hline Poor (\%) & 5.4 & 17.6 \\
\hline Near-poor (\%) & 18.1 & 18.7 \\
\hline Non-poor (\%) & 69.5 & 36.7 \\
\hline
\end{tabular}

Urban: Poor: monthly capita $<143$ Yuan (or US $\$ 0.60$ per day); nearpoor: 144-286 Yuan; non-poor: $>286$ Yuan

Rural: Poor: monthly capita $<54$ Yuan (or US $\$ 0.22$ per day); near-poor: 53-83 Yuan; non-poor: >83 Yuan.

${ }^{*}$ US $\$=8.23$ Yuan.

needed to provide basic needs. The income poverty criteria vary by province. For example, in urban areas of Sichuan, poverty is defined as monthly per capita income less than 143 Yuan (or US $\$ 0.60$ per day). ${ }^{11}$ In rural areas, poverty is defined as monthly per capita income less than 54 Yuan (or US $\$ 0.22$ per day). These poverty definitions are less than the World Bank's definition of US\$1 per person per day. We further define near poverty as $200 \%$ of the poverty level definition (144-286 Yuan for urban and 53-83 Yuan for rural, depending on the province). Among the households surveyed, $5.4 \%$ of urban households and $17.6 \%$ of rural households met the poverty definition. About $18 \%$ of households in each area sample met the definition for near poverty.

Major household expenditures include food, housing, clothing, education, and other items. Cigarette consumption is not considered a necessity within the household consumption category. However, it is the focus of this study. Table 2 presents household expenditure patterns for these major expenditures and cigarette consumption status by urban versus rural households and further separated by these income groups.

As shown in table 2, for both urban and rural households, the higher the household income, the higher the cigarette expenditures. These higher cigarette expenditures are reflected in both the amount of cigarette consumption and the price per pack paid by different income households. For example, the urban poor households consumed 7.6 packs of cigarettes a month, the urban near-poor households consumed 9.8 packs a month, and the urban non-poor households consumed 15.5 packs a month. Overall, the rural households consumed more cigarettes than urban households: 21.8 packs a month for the rural poor households, 24.1 packs for the rural near-poor, and 28.8 packs for the rural non-poor.

However, significant differences are seen in the average prices paid per pack of cigarettes by smokers: 3.8 Yuan for the urban poor households, 4.7 Yuan for the urban near-poor households, and 8.2 Yuan for the urban non-poor households. On the other hand, the price per pack in rural areas ranged from 1.1 Yuan for the poor households to 1.7 Yuan for the non-poor households, a much narrower price difference. As a result, monthly cigarette expenditures were much higher for non-poor than for poor households.

Table 2 indicates that urban higher income households spent more (four times) on cigarettes than low income urban households, largely because they purchased more expensive cigarettes, including foreign brands in some cases. Rural high income households spent more (two times) on cigarettes than rural low income households, largely because they consumed more cigarettes, with the price paid per pack showing less variation across rural income groups. Further, urban and rural smokers differed greatly in both the number of cigarettes consumed and price paid per pack: urban smokers smoked fewer cigarettes than rural smokers, and they paid much higher prices per pack.

Beyond understanding differences in smoking behaviour, it is useful to examine how cigarette expenditures differ as a percentage of total expenditures across the different household income groups as shown in table 2. Among urban smoking households, cigarette expenditures accounted for an average of $6.6 \%$ of total expenditures of poor households,

Table 2 Urban and rural household monthly income expenditure patterns and smoking information, 2002

\begin{tabular}{|c|c|c|c|c|c|c|}
\hline & \multicolumn{3}{|l|}{ Urban } & \multicolumn{3}{|l|}{ Rural } \\
\hline & $\begin{array}{l}\text { Poor } \\
(n=140)\end{array}$ & $\begin{array}{l}\text { Near-poor } \\
(n=463)\end{array}$ & $\begin{array}{l}\text { Non-poor } \\
(n=1972)\end{array}$ & $\begin{array}{l}\text { Poor } \\
(n=146)\end{array}$ & $\begin{array}{l}\text { Near-poor } \\
(n=149)\end{array}$ & $\begin{array}{l}\text { Non-poor } \\
(n=534)\end{array}$ \\
\hline \multicolumn{7}{|l|}{ Income (Yuan) and smoking information } \\
\hline Income & 502 & 780 & 2769 & 226 & 325 & 863 \\
\hline Cigarette expenditures (Yuan)* & 29 & 46 & 127 & 24 & 29 & 49 \\
\hline Percentage of income on cigarettes (\%) & $5.8 \%$ & $5.9 \%$ & $4.6 \%$ & $7.1 \%$ & $8.9 \%$ & $5.7 \%$ \\
\hline Cigarette consumption (no of packs) & 7.6 & 9.8 & 15.5 & 21.8 & 24.1 & 28.8 \\
\hline Price per pack (Yuan) & 3.8 & 4.7 & 8.2 & 1.1 & 1.2 & 1.7 \\
\hline \multicolumn{7}{|l|}{ Total expenditures (Yuan) } \\
\hline Total expenditures & 441 & 689 & 1392 & 212 & 292 & 582 \\
\hline Food (\%) & 60.3 & 54.9 & 40.5 & 61.8 & 59.2 & 42.4 \\
\hline Housing (\%) & 3.6 & 4.2 & 8.8 & 2.3 & 2.4 & 7.7 \\
\hline Education (\%) & 6.6 & 5.4 & 11.0 & 9.5 & 10.6 & 15.5 \\
\hline Clothing (\%) & 5.7 & 4.5 & 10.3 & 5.7 & 6.5 & 6.7 \\
\hline Cigarettes (\%) & 6.6 & 6.7 & 9.1 & 11.3 & 9.9 & 8.4 \\
\hline Other (\%) & 17.2 & 24.3 & 20.3 & 9.4 & 4.9 & 19.3 \\
\hline
\end{tabular}

Urban: Poor: monthly capita $<143$ Yuan (or US $\$ 0.60$ per day); near-poor: 144-286 Yuan; non-poor: $>286$ Yuan.

Rural: Poor: monthly capita $<54$ Yuan (or US\$0.22 per day); near-poor: 53-83 Yuan; non-poor: $>83$ Yuan.

*US\$ $=8.23$ Yuan. 
$6.7 \%$ for near-poor smoking households, and $9.1 \%$ for nonpoor smoking households. Among rural smoking households, cigarette expenditures averaged $11.3 \%$ of the total household expenditures of poor households, $9.9 \%$ for near-poor smoking households, and $8.4 \%$ for non-poor households. These figures imply that in urban areas, cigarettes are a luxury good, with cigarette expenditures increasing as a percent of total expenditures as income increases. However, the opposite is true in rural areas-as income rises, cigarette expenditures decrease as a percentage of total expenditures, a so-called "normal good".

The patterns are more consistent across rural and urban areas when one looks at the percentage of total income (rather than expenditures) spent on cigarette consumption. In both urban and rural areas, this percentage is higher for poor households than for non-poor households, but highest of all for near-poor households. Urban poor households spent 5.8\% of their reported income on cigarettes compared to $4.6 \%$ in urban non-poor households, and 5.9\% in near-poor households. The differences are wider among rural households, with $7.1 \%$ spent in poor households, $8.9 \%$ in the near-poor households, and $5.7 \%$ for non-poor households.

\section{REGRESSION ANALYSIS}

Using the total sample of households, a regression model was used to estimate the impact of smoking status on total household expenditures minus cigarette expenditures. The main components of interest were food expenditures, housing expenditures, clothing expenditures, and education expenditures.

In examining the impact of smoking on household expenditures, a number of key explanatory variables help determine household expenditures. These include household income, size of the household, age and educational level of the head of the household, and smoking status. As income increases, urban households and rural households may show different patterns of change in spending on food, housing, and clothing because tastes and opportunities to expand income are quite different. Thus, an interaction term was introduced in the model. Smoking status was measured in two different forms: number of packs smoked per month and the amount of cigarette expenditures per month, by each household. The amount of household expenditures is directly associated with the size of the household; thus, both dependent variable expenditures and explanatory income variables were adjusted by household size. It would be ideal to use age adjusted equivalent weighted household size to analyse household expenditures functions. Unfortunately, the survey data do not include the age distribution information. A general regression model was specified as follows:

$\mathrm{E}_{\mathrm{i}}=\mathrm{b}_{0}+\mathrm{b}_{1} \mathrm{SM}+\mathrm{b}_{2} \mathrm{In}+\mathrm{b}_{3}$ Age $+\mathrm{b}_{4} \mathrm{Ed}+\mathrm{b}_{5} \mathrm{HS}+\mathrm{b}_{6} \mathrm{UR}+$ $\mathrm{b}_{7} \mathrm{UR}^{*} \mathrm{In}+\mathrm{U}_{\mathrm{i}}$

Where $\mathrm{E}_{\mathrm{i}}$ : Per capita total household expenditures minus cigarette expenditures
Per capita food expenditures

Per capita housing expenditures

Per capita clothing expenditures

Per capita educational expenditures

SM: Smoking status - number of packs smoked

In: Per capita household income

Age: Age of head of household (years)

Ed: Years of education of head of household

HS: Household size (number of individuals)

UR: Urban location $(=1)$ versus rural $(=0)$

$U^{*}$ In: Interaction term between urban and income

$\mathrm{U}_{\mathrm{i}}$ : Error terms.

The coefficient for smoking status, $b_{1}$, provides information about the magnitude of the impact of smoking status on household expenditures, holding other variables constant. Age, education, household size, and location (urban) are other important variables that could explain the household expenditure pattern.

As shown in table 3, on average, each additional pack of cigarettes per month would reduce other household expenditures by 2.9 Yuan per capita (between 9-12 Yuan per household) per month. The effect can be separately estimated for each major category of expenditures: each pack of cigarettes reduces expenditures by 0.5 Yuan per capita per month on food, 0.4 Yuan per capita per month on housing, 0.2 Yuan per capita per month on clothing, and 0.15 Yuan per capita per month on education. While the coefficients are small, the actual impact is quite considerable, since an urban household that buys 15 packs per month would spend 7.5 Yuan per capita less on food, 6 Yuan per capita less on housing, 3 Yuan per capita less on clothing, and 2.25 Yuan per capita less on education, controlling for the variables included in the regression. If rural households bought 20 packs per month, they would spend 10 Yuan per capita less on food, 8 Yuan per capita less on housing, 4 Yuan per capita less on clothing, and 3 Yuan per capita less on education. All these coefficients are significant at less than $1 \%$ level, two tailed test. The positive coefficient of the interaction term between income and the urban dummy variable shows that urban households tended to spend more when there was additional income than rural households. Also as expected, larger households had lower per capita household expenditures, after controlling for per capita income, reflecting scale economies in the household.

\section{POLICY IMPLICATIONS}

The survey results indicate that low income households bought much lower priced cigarettes than high income households in China. Lower income households also smoked fewer cigarettes than high income households, especially in rural households. However, given their relatively low income, households under the poverty level allocated a higher percentage of their income for cigarettes than did non-poor households. The analysis shows a clear reduction in spending

\begin{tabular}{lccccc} 
Table 3 & Impact of cigarette consumption on household expenditures $(\mathrm{n}=3402)$ \\
\hline & $\begin{array}{l}\text { Total expenditures } \\
\text { (minus tobacco) }\end{array}$ & Food & Housing & Clothing & Education \\
\hline Age & $-1.27^{*}$ & -0.01 & $-0.55^{*}$ & $-0.46^{*}$ & $0.47^{*}$ \\
Household size & $-41.52^{*}$ & $-19.59^{*}$ & $-8.39^{*}$ & $-8.33^{*}$ & $-13.52^{*}$ \\
Education level & $33.30^{*}$ & $20.39^{*}$ & 4.00 & $4.07^{*}$ & $6.93^{*}$ \\
Income per capita & $0.06^{*}$ & $0.02^{*}$ & $0.01^{*}$ & 0.00 & $0.02^{*}$ \\
Amount of cigarette consumption & $-2.90^{*}$ & $-0.48^{*}$ & $-0.40^{*}$ & $-0.21^{*}$ & $-0.15^{*}$ \\
Urban* income & $0.16^{*}$ & $0.03^{*}$ & $0.02^{*}$ & $0.02^{*}$ & 0.00 \\
Urban & $-42.93^{*}$ & $28.11^{*}$ & -5.02 & 4.67 & -4.67 \\
Constant & $318.79^{*}$ & $100.27^{*}$ & $63.68^{*}$ & $57.86^{*}$ & $57.94^{*}$ \\
Adjusted $R^{2}$ & 0.4856 & 0.4511 & 0.1483 & 0.3575 & 0.2918 \\
\hline *Indicates coefficient is significant at $\mathrm{p}<0.01$, two tailed test. & & & \\
\hline
\end{tabular}


on other goods in smoking households. Therefore, if households stopped buying cigarettes and spent the money on other goods instead, households could improve their overall standard of living. This is especially true for poor households.

One policy issue is the effect that higher cigarette taxes would have on low income households versus high income households - that is, whether higher taxes would impose an undue burden on low income households. Four factors would affect the tax impact: (1) cigarette prices paid by people with different income levels; (2) amount of cigarette consumption at different income levels; (3) their respective price elasticity of demand for cigarettes; and (4) the type of tax imposed on cigarette consumption. ${ }^{10} 11$

Smokers in lower income households in China paid less per pack and smoked fewer cigarettes than higher income smokers, and low income smokers had higher price elasticity than higher income smokers: -1.9 for low income households, -0.7 for middle income households, and 0.5 for high income households. ${ }^{12}$ The additional financial burden caused by a tax increase would be much less for low income households than for high income households. If the tax is a fixed percentage of cigarette price, as with an ad valorem tax, instead of a specific tax, which is a fixed amount on each pack regardless of its price, then the additional tax burden from a tax rate increase on low income households would be even lower. For instance, using table 2 as an example, a 0.40 Yuan specific tax increase per pack would become a $10.5 \%$ (0.40/3.8 Yuan) per pack price increase for poor urban households, an $8.5 \%$ (0.4/4.7 Yuan) price increase for nearpoor households, and a 7.8\% (0.4/8.2 Yuan) increase for nonpoor households. Given the different price elasticities, the poor smokers would reduce consumption by $20 \%$, near-poor households by $5 \%$, and non-poor households by only $2 \%$. So the "average" poor household that bought 17 packs of cigarettes per month at 3.8 Yuan per pack, or 64.6 Yuan, when faced with a $10.5 \%$ price increase, would buy 14 packs per month at 4.2 Yuan, and spend a smaller total of 58.8 Yuan per month after the tax increase. An average non-poor household that bought 18 packs per month at 8.2 Yuan, spending a total of 147.6 Yuan, would decrease consumption very little after the tax increase. If these households bought the same number of packs each month, total spending would rise to 154.8 Yuan; if they cut back by one pack per month, total spending would be reduced very slightly to 146.2 Yuan per month. On the other hand, based on the average price per pack of cigarettes paid by different income groups, as shown in table 2, the effect of an across the board 10\% increase in price, such as an ad valorem tax, would be that poor household smokers would pay an extra 0.38 Yuan per pack, near-poor household smokers would pay an additional 0.47 Yuan per pack, and non-poor smokers would pay 0.82 Yuan more per pack. The reduction in cigarette consumption, according to their different price elasticities, would be 19\% for poor smokers, 7\% for near-poor smokers, and 5\% for nonpoor smokers, respectively. Total monthly spending on cigarettes for the "average" poor smoker would fall from 64.4 Yuan to 56.8 Yuan (13.6 packs at 4.18 Yuan each), whereas the average non-poor smokers would buy one pack less, but the price increase would mean total spending would increase from 147.6 to 153.3 Yuan. The ad valorem type tax is more efficient at shifting the tax burden from poor to nonpoor households.

Currently China levies a fixed $64 \%$ tax at the producer level, equivalent to a $38 \%$ tax at the retail level. ${ }^{13}$ This is a
What this paper adds

Information on the effect of smoking on household living standards in developing countries is very limited. This paper has provided detailed information about the negative impact of smoking on household living standards, especially for low income households in China. Additionally, findings indicate that the relative financial burden for low income households is lower than high income households from additional taxation on cigarette.

relatively low rate compared to the cigarette tax rate around the world. ${ }^{10}$ The analysis of these survey data suggests that raising cigarette tax rates in China would reduce consumption more among low income households than among high income households, increasing available household funds for other major household items, such as food, housing, clothing, and education. Furthermore, an ad valorem tax instead of a specific tax would lower the financial burden of a higher cigarette tax on low income households, and in this respect would be more "pro-poor".

\section{ACKNOWLEDGEMENTS}

This study was funded by the International Development for Research Center/Research Institute for Tobacco Control, the World Bank, Rockefeller Foundation, and Fogarty International Center/ National Institutes of Health. (Grant No. R01-TW05938)

\section{Authors' affiliations}

T-w Hu, University of California, Berkeley, California, USA

Z Mao, Sichuan University, Sichuan, China

Y Liu, Harvard University, Cambridge, Massachusetts, USA

J de Beyer, World Bank, Washington DC, USA

M Ong, Stanford University, Stanford, California, USA

Competing interests: none declared

\section{REFERENCES}

1 Collins D, Lapsley $\mathrm{H}$. The economic impact of smoking. 1997. http:// www.globalink.org/tobacco/9910eco/ (Accessed October 10, 2002).

2 Rice D, Kelman S, Miller L. Economic costs of smoking. In: Cartwright WS, Kaple JM, eds. Economic costs, cost-effectiveness, financing and communitybased drug treatment. NIDA Monograph Series. no.113, 10-32, 1991.

3 Miller LS, Zhang X, Rice DP, et al. State estimates of total medical expenditures attributable to cigarette smoking, 1993. Public Health Reports 1998; 113:447-58.

4 Miller VP, Ernst C, Collin F. Smoking-attributable medical care costs in the USA. Soc Sci Med 1999;48:375-91.

5 Siahpush M, Borland R, Scollo M. Smoking and financial stress. Tobacco Control 2003; 12:60-6.

6 Efroymson D, Ahmed S, Townshend J, et al. Hungry for tobacco: an analysis of the economic impact of tobacco consumption on the poor in Bangladesh. Tobacco Control 2001; 10:212-17.

7 Gong YL, Koplan JP, Wei Feng, et al. Cigarette smoking in china: prevalence, characteristics, and attitudes in Minhang District. JAMA 1995;274:1232-3.

8 Hu T W, Mao Z. Effects of cigarette tax on cigarette consumption and the Chinese economy. Tobacco Control 2002;11:105-8.

9 Bobak M, Jha P, Nguyen S, et al. Poverty and smoking. Tobacco control in developing countries. Oxford: Oxford University Press, 2000:41-61.

10 Chaloupka F, Hu TW, Warner K, et al. The taxation of tobacco products. Tobacco control in developing countries. Oxford: Oxford University Press, 2000:237-72.

11 Sunley E, Yurekli A, Chaloupka F. The design, administration, and potential revenue of tobacco excises. Tobacco control in developing countries. Oxford: Oxford University Press, 2000:409-26.

12 Mao ZZ, Yang GH, MA JM, et al. Adult's demand for cigarettes and its determinants in China (in Chinese). Soft Science of Health 2003;17:19-23.

13 Hu TW. Cigarette taxation in China: lessons from international experiences. Tobacco Control 1997;6: 136-40. 